Research Article

Xuan Li*, Yu Cong, Jisheng Sui, and Xiaolong Li

\title{
An investigation on the degradation behaviors of Mg wires/PLA composite for bone fixation implants: influence of wire content and load mode
}

https://doi.org/10.1515/secm-2021-0005

Received Sep 21, 2020; accepted Jan 06, 2021

\begin{abstract}
Poly-lactic acid based biocomposite strengthened with magnesium alloy wires (Mg wires/PLA composite) is prepared for bone fixation implantation. The influence of wire content and load mode on the degradation performances of the composite and its components is studied. The result suggests the degradation of $\mathrm{Mg}$ wires could slow down the $\mathrm{pH}$ decrease originated from the degradation of PLA, while a relatively high wire content contributes to descend the degradation rate of $\mathrm{Mg}$ wire in the composite. Dynamic load significantly promotes the mechanical loss of the specimens. After 30 days immersion, the $S_{b}$ retention is about $65 \%, 52 \%$ and $55 \%$, respectively for pure PLA, the composite at $10 \mathrm{vol} \%$ and $20 \mathrm{vol} \%$ under dynamic load, comparing to $75 \%, 70 \%$ and $72 \%$ under no load. Moreover, dynamic load could further mitigate the degradation of $\mathrm{Mg}$ wires by increasing convective transport of acidic products out of the composite.
\end{abstract}

Keywords: biodegradable; biomaterials; composites; degradation behaviors

\section{Introduction}

Biodegradable polymers, including poly-lactic acid (PLA) and poly-glycolic acid (PGA), are considered as one of the important and applicable biomaterials used for implants [1]

\footnotetext{
${ }^{\star}$ Corresponding Author: Xuan Li: School of Materials Science and Engineering, Nanjing Institute of Technology, Nanjing, 211167, China; Jiangsu Key Laboratory of Advanced Structural Materials and Application Technology, Nanjing Institute of Technology, Nanjing, 211167, China; Email: lx@njit.edu.cn

Yu Cong: Department of Orthopedics, Jinling Hospital, School of medicine, Nanjing University, Nanjing, 210002, China

Jisheng Sui: Department of Orthopedics, Nanjing First Hospital of Nanjing Medical University, Nanjing 210006, China

Xiaolong Li: Department of Orthopedics, The affiliated Wujin Hospital of Jiangsu University, Changzhou 213002, China
}

The main hurdles of biodegradable polymers in service for bone fixation implants are the lack of bioactivity, inflammation induced by a significant $\mathrm{pH}$ decrease and the relatively low mechanical properties [2]. For instance, the acidic degradation products of PLA are noticed to induce a mild inflammation response, resulting in a continuous fibrous capsule with a dense population of fibroblast-like cells around the PLLA screw implant [3]. Many studies try to overcome these drawbacks by adding components such as HA [4] or bioglass [5] into the polymeric matrix. Very recently, the biodegradable polymer based composite reinforced with magnesium additives attracts huge interests [69]. It is reported the mechanical properties and the acidic degradation of polymers could be significantly improved with the corporation of $\mathrm{Mg}$ additives. Moreover, the presence of $\mathrm{Mg}$ could profoundly promote the fracture healing by enhancing mineralization and osteogenesis [10]. Besides those, the $\mathrm{Mg}$ additives would also benefit from the protection of surround polymer matrix to avoid rapid degradation [7] and lactate could further elicit ER-Mitochondrial $\mathrm{Mg}^{2+}$ dynamics to integrate cellular metabolism [11]. The composite shows potential applications for the implants.

In service, the implants are desired to have tailored degradation rate to match the healing process of the fracture tissues. Therefore, the degradation performances, specially the degradation behaviors of the composite are of importance. Apparently, the degradation performances of the composite strongly depend on the degradation of its components, involving the hydrolysis of the polymeric matrix and the biodegradation of $\mathrm{Mg}$ additives. It is well known that the hydrolysis rate of the polymeric matrix is strongly related to $\mathrm{pH}$ values, where acidic or alkaline environment could both accelerate the hydrolysis [12]. Since the degradation of $\mathrm{Mg}$ would release excess $\mathrm{OH}^{-}$ions to raise the $\mathrm{pH}$ values, its content would be of importance for the degradation of the composite. Meanwhile, as the main supports of the composite, the degradation behaviors of $\mathrm{Mg}$ additives directly influence the mechanical property retention of the composite. Therefore, the degradation behaviors of each

ə Open Access. (c) 2021 X. Li et al., published by De Gruyter. (cc) BY This work is licensed under the Creative Commons Attribution 4.0 License 


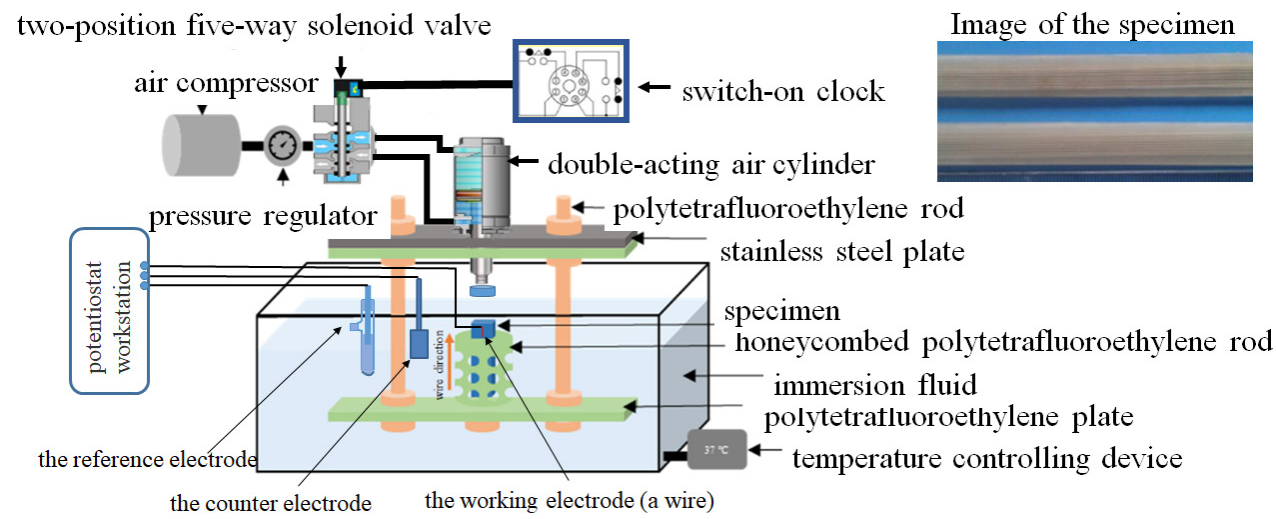

Figure 1: Schematic illustration of the apparatus used in the test and the right-upper picture is the image of the specimen.

component in the composite should be taken into account for further applications.

Moreover, it should be mentioned that the implant would suffer different physiologically mechanical loads in vivo which would complicate the degradation process of the composite. Commonly, it is reported that these loads would play an important role on tissue healing [13-15]. For example, dynamic loading is reported to profoundly promote bone fracture repair by enhancing the bone formation [16]. Numerous investigations show the load would obviously affect the degradation of pure biodegradable polymers $[17,18]$ or Mg alloys [19, 20]. However, the relative studies on the composite, specially the degradation behaviors of its components are scarce. In this work, magnesium alloy wires are conducted to unidirectionally strengthen PLA matrix (Mg wires/PLA). The effects of wire content and load mode on the degradation behaviors of the composite and its components are studied.

\section{Materials and methods}

\subsection{Materials}

Commercial PLA particles were purchased from Natureworks LLC. The diameter of AZ31B magnesium alloy wire is $0.3 \mathrm{~mm}$. The wires were self-fabricated by cold-drawing process. WHD-30 type micro arc oxidization (MAO) equipment was conducted on the $\mathrm{Mg}$ wires to improve the interface adhesion between the wires and the PLA matrix [21]. The composite with a volume fraction of $\mathrm{Mg}$ wires at 10 vol $\%$ and $20 \mathrm{vol} \%$ were prepared by a laminating method described in our previous work [22], while pure-PLA was prepared under the same condition.

\subsection{Immersion tests}

The immersion tests of the specimen were conducted under different load modes, including no load, static compression load at $1 \mathrm{MPa}$ (static load), and dynamic compression load at $1 \mathrm{MPa}$ and $1 \mathrm{~Hz}$ (dynamic load). The dimension of the specimen for the tests was $50 \mathrm{~mm} \times 12 \mathrm{~mm} \times 2 \mathrm{~mm}$. Kirkland's bio-corrosion media (KBM) [23] with a $\mathrm{pH} 7.4$ and temperature $37^{\circ} \mathrm{C}$ was applied as the immersion solution. The ratio of solution's volume to sample's surface area was larger than $50 \mathrm{ml} / \mathrm{cm}^{2}$. During the immersion, the solution was changed every day and the $\mathrm{pH}$ value was recorded before each changing. The home-made apparatus for applying the loading was shown in Figure 1. The switch-on clock and the pressure regulating valve was used to control the loading frequency and magnitude, respectively. The immersion durations were predetermined to be 7 days, 14 days, 21 days and 30 days. At least three specimens were performed for each parameter and the averages were presented in the assessment.

\subsection{Mechanical and thermal tests}

Tensile tests were performed to determine the tensile strength $\left(\mathrm{S}_{t}\right)$ and elastic modulus $(\mathrm{E})$ at the longitudinal direction. Three-point bending tests based on the standard ASTMD790-2010 were conducted to determine the bending strength $\left(S_{b}\right)$ of the specimens along the transverse direction. The tests were performed by using a CMT4503 electronic universal testing machine at room temperature. During the bending test, the crosshead speed is $2 \mathrm{~mm} / \mathrm{min}$ with a bending span of $32 \mathrm{~mm}$. The $S_{b}$ retention was obtained by dividing the initial $S_{b}$ with the $S_{b}$ of the immersed specimen.

The thermal behaviors of PLA matrix were determined on a differential scanning calorimeter equipment 
(DSC404F3). The test was performed under a nitrogen atmosphere, and the heating rate is $10^{\circ} \mathrm{C} / \mathrm{min}$ from $30^{\circ} \mathrm{C}$ to $210^{\circ} \mathrm{C}$. The relevant thermal transitions respectively reflect the glass transition $\left(T_{g}\right)$, cold crystallization $\left(T_{c c}\right)$, and melting $\left(T_{m}\right)$. After the test, $T_{g}$ was got by using the midpoint of the transformation, while the crystallinity $X_{c}$ of PLA matrix was measured according to the following equation:

$$
X_{c}=\left(\Delta H_{m}-\Delta H_{c c}\right) / \Delta H_{0}
$$

where $\Delta H_{m}$ reflects the enthalpy of melting, $\Delta H_{c c}$ reflects the enthalpy of cold crystallization, and $\Delta H_{0}$ is the enthalpy of $100 \%$ crystalline PLLA (about $93.1 \mathrm{~J} / \mathrm{g}$ ) [7].

\subsection{Electrochemical tests}

Electrochemical impedance spectroscopy (EIS) was performed on a $\mathrm{CHI} 604$ potentiostat workstation to investigate the degradation performance of $\mathrm{Mg}$ wires in the composite. A classical three-electrode system was used, where a $\mathrm{Mg}$ wire at the middle of the composite acts as the working electrode, a platinum plate is used as the counter electrode, and a saturated calomel electrode (SCE) is conducted as the reference electrode, as shown in Figure 1. The EIS was measured from 100,000 to $0.1 \mathrm{~Hz}$ with $10 \mathrm{mV}$ perturbation.

\subsection{Microstructural characterization}

After the immersion, the composite is dissolved in chloroform to collected the $\mathrm{Mg}$ wires in the composite. Scanning electron microscopy (SEM, the Philips XL30 FEG) was performed to investigate the surface morphologies of the wires during the degradation.

XR-CT analysis using a CT system (Y.CT PRECISION, voltage $195 \mathrm{kV}$, current $0.28 \mathrm{~mA}$ ) was conducted to represent the morphologies of the composite. The internal defects were calculated by using VGStudio Max 3.0 analysis software. Detailed analysis procedure is described in another work [9].

\section{Results}

\subsection{Evolution of degradation properties for the composite}

The $\mathrm{pH}$ evolution in the solutions of pure PLA and the composite during immersion are represented in Figure 2. $\mathrm{pH}$ changes slightly under no load, but decreases significantly under the loading conditions for both pure-PLA and the composite. In the case of the composite, an apparent $\mathrm{pH}$ decrease is noticed under dynamic load during the first 10 days, as the arrow shown in Figure 2(b) and 2(c). For the composite at $20 \mathrm{vol} \%$, the $\mathrm{pH}$ drops to about 5.8 after 10 days immersion under dynamic load while it is about 7.4 and 6.5 respectively under no load and static load. Thereafter, $\mathrm{pH}$ values increase gradually, indicating the mitigation on $\mathrm{pH}$ decrease by the degradation of Mg wires.

The initial mechanical properties of pure PLA and the composite are shown in Table 1. It could be noticed that increasing the $\mathrm{Mg}$ wire content could significantly enhance the mechanical properties of the composite. Figure 3 shows

Table 1: Initial mechanical properties of pure PLA and the composite.

\begin{tabular}{cccc}
\hline & $\mathrm{S}_{t}(\mathrm{MPa})$ & $\mathrm{E}(\mathrm{GPa})$ & $S_{b}(\mathrm{MPa})$ \\
\hline Pure PLA & $45( \pm 4.66)$ & $4.0( \pm 0.37)$ & $76( \pm 2.52)$ \\
$\begin{array}{c}\text { The composite } \\
\text { at 10 vol\% }\end{array}$ & $67( \pm 2.32)$ & $6.2( \pm 1.61)$ & $119( \pm 2.61)$ \\
$\begin{array}{c}\text { The composite } \\
\text { at 20 vol\% }\end{array}$ & $83( \pm 4.51)$ & $8.1( \pm 1.32)$ & $159( \pm 4.01)$ \\
\hline
\end{tabular}
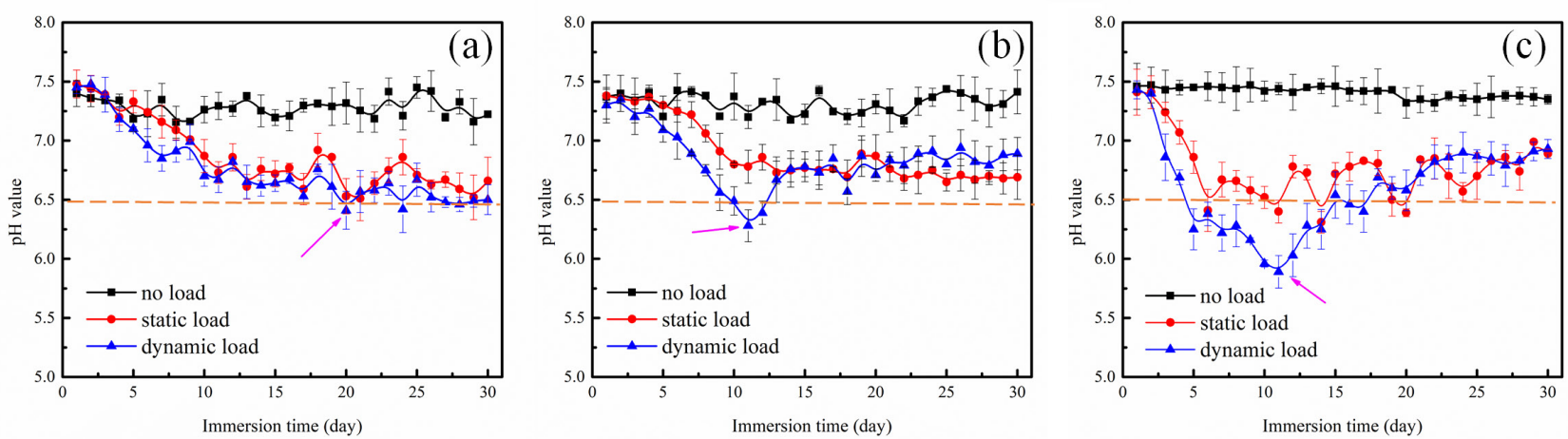

Figure 2: pH changes in the fluid for the different specimens: (a) pure PLA; (b) the composite at 10 vol\%; (c) the composite at 20 vol\%. 

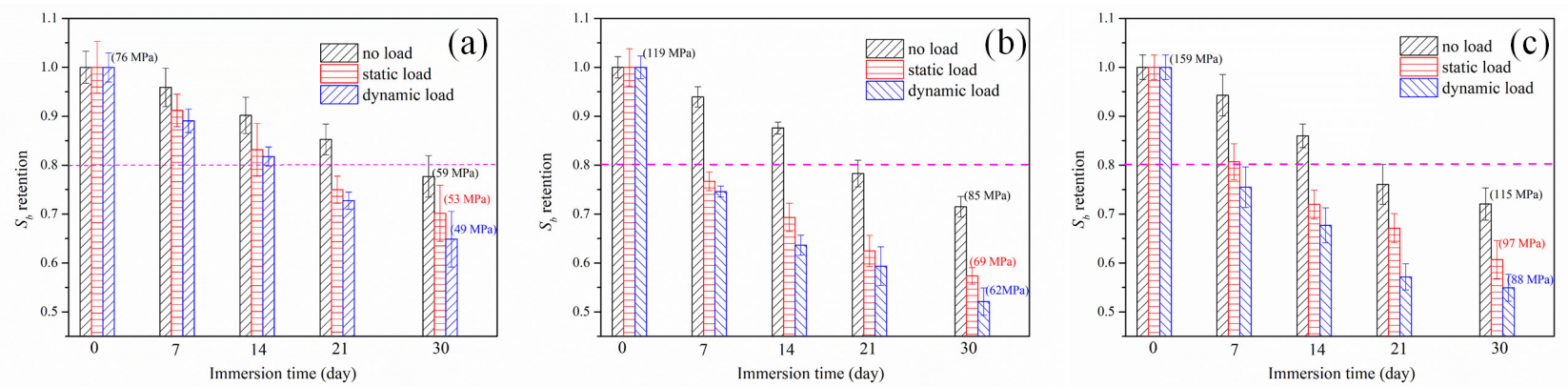

Figure 3: $S_{b}$ retention changes of the different specimens: (a) pure PLA; (b) the composite at 10 vol\%; (c) the composite at 20 vol\%.

the changes of $S_{b}$ retention for pure PLA and the composite during the immersion. The initial $S_{b}$ of pure PLA is about $75 \mathrm{MPa}$, while it increases to about $119 \mathrm{MPa}$ and $159 \mathrm{MPa}$, respectively at $10 \mathrm{vol} \%$ and $20 \mathrm{vol} \%$ for the composite. $\mathrm{Mg}$ wires could apparently raise the mechanical properties of PLA. After immersion for 30 days, the $S_{b}$ of pure PLA reduces to about $59 \mathrm{MPa}, 53 \mathrm{MPa}$ and $49 \mathrm{MPa}$, respectively under no load, static and dynamic load. Similarly, dynamic load would also promote the $S_{b}$ reduction of the composite. As the immersion proceeds to 30 days, the $S_{b}$ retention is about $65 \%, 52 \%$ and $55 \%$, respectively for pure PLA, the composite at $10 \mathrm{vol} \%$ and $20 \mathrm{vol} \%$ under dynamic load, comparing to $75 \%, 70 \%$ and $72 \%$ under no load. Moreover, it could be noticed that the strength of composite decreased faster than that of PLA at the same condition, though the
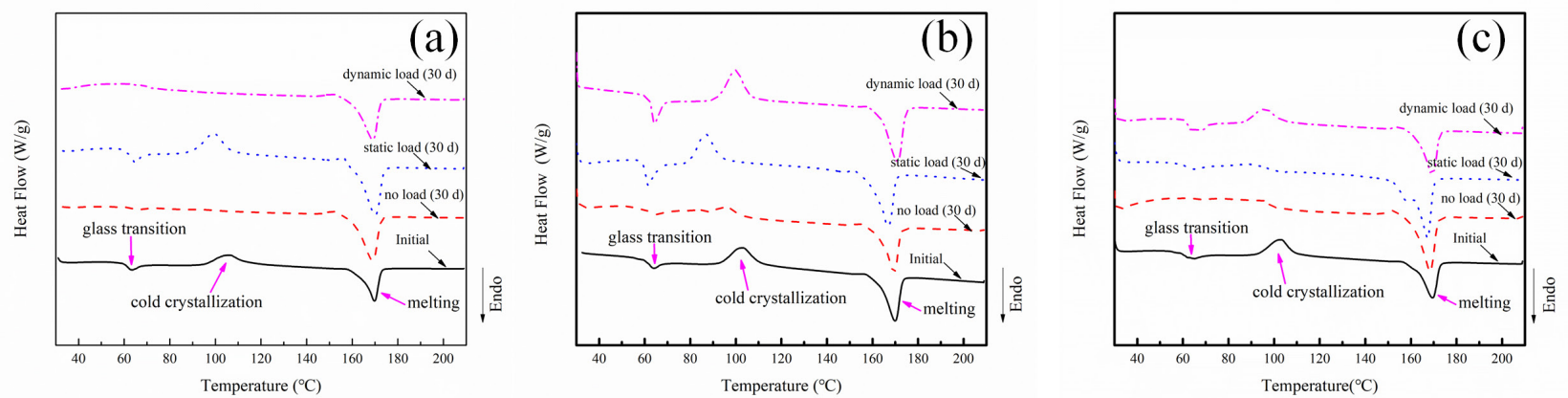

Figure 4: DSC curves of pure PLA and PLA matrix in the composite at initial and immersion for 30 days under different load modes: (a) pure PLA; (b) PLA matrix in the composite at 10 vol\%; (c) PLA matrix in the composite at 20 vol\%.

Table 2: The thermal properties of pure PLA and the PLA matrix in the composite under different load modes.

\begin{tabular}{ccccccc}
\hline & \multicolumn{2}{c}{ Pure PLA } & \multicolumn{2}{c}{ PLA matrix at 10 vol\% } & \multicolumn{2}{c}{ PLA matrix at 20 vol\% } \\
& $T_{m}\left({ }^{\circ} \mathrm{C}\right)$ & $X_{c}(\%)$ & $T_{m}\left({ }^{\circ} \mathrm{C}\right)$ & $X_{c}(\%)$ & $T_{m}\left({ }^{\circ} \mathrm{C}\right)$ & $X_{c}(\%)$ \\
\hline initial & 169.87 & 34 & 169.84 & 33 & 169.56 & 30 \\
no load (30 days) & 168.82 & 43 & 169.37 & 42 & 168.41 & 43 \\
static load (30 days) & 170.06 & 43 & 166.88 & 39 & 167.33 & 44 \\
dynamic load (30 days) & 169.00 & 45 & 171.01 & 40 & 169.32 & 41 \\
\hline
\end{tabular}


the external loads have slight influence on the crystalline fraction of PLA matrix.

\subsection{Evolution of $\mathbf{M g}$ wires performances in the composite}

Figure 5(a) and 5(b) depicts the Nyquist plots of the wires in the composite under different load modes after 14 days immersion. The spectra are fitted with the equivalent circuit model in right-upper image of Figure 5(a) and 5(b). A constant phase element (CPE) instead of an ideal capacitor is conducted. The CPE represents the surface inhomogeneity [24] and $\mathrm{R}_{\text {sol }}$ means the resistance of the solution. As the immersion proceeds, the changing of polarization resistance $\left(\mathrm{R}_{p}\right)$ of the wire in the composite is shown in Figure 5(c) and 5(d). After 1 day, the $\mathrm{R}_{p}$ is about $6000 \Omega \mathrm{cm}^{2}$. As the immersion proceeds to 7 days, the $\mathrm{R}_{p}$ raises and the largest $\mathrm{R}_{p}$ appears under the dynamic load. Thereafter, $\mathrm{R}_{p}$ at no load increases initially and then descends gradually. As a comparison, $\mathrm{R}_{p}$ decreases continually under the static load. For the composite under dynamic load, $\mathrm{R}_{p}$ represents a dramatically increase after 30 days immersion. Moreover, the $\mathrm{R}_{p}$ at $20 \mathrm{vol} \%$ seems to have a larger value than that at $10 \mathrm{vol} \%$ after 30 days immersion under different load modes.

Figure 6(a-f) depicts the surface morphologies of the wires in the composite at $10 \mathrm{vol} \%$ by dissolving the PLA matrix in chloroform. The surface coating is almost integral while only micro cracks could be observed after 7 days immersion. However, as the immersion time increases to 30 days, the coating exhibits more critical breakage under static and dynamic load comparing to that under no load, indicating the external load would enhance the breakage of the coating. Figure $6(\mathrm{~g}-\mathrm{l})$ depicts the surface morphologies of the wires in the composite at $20 \mathrm{vol} \%$. Similarly, dynamic
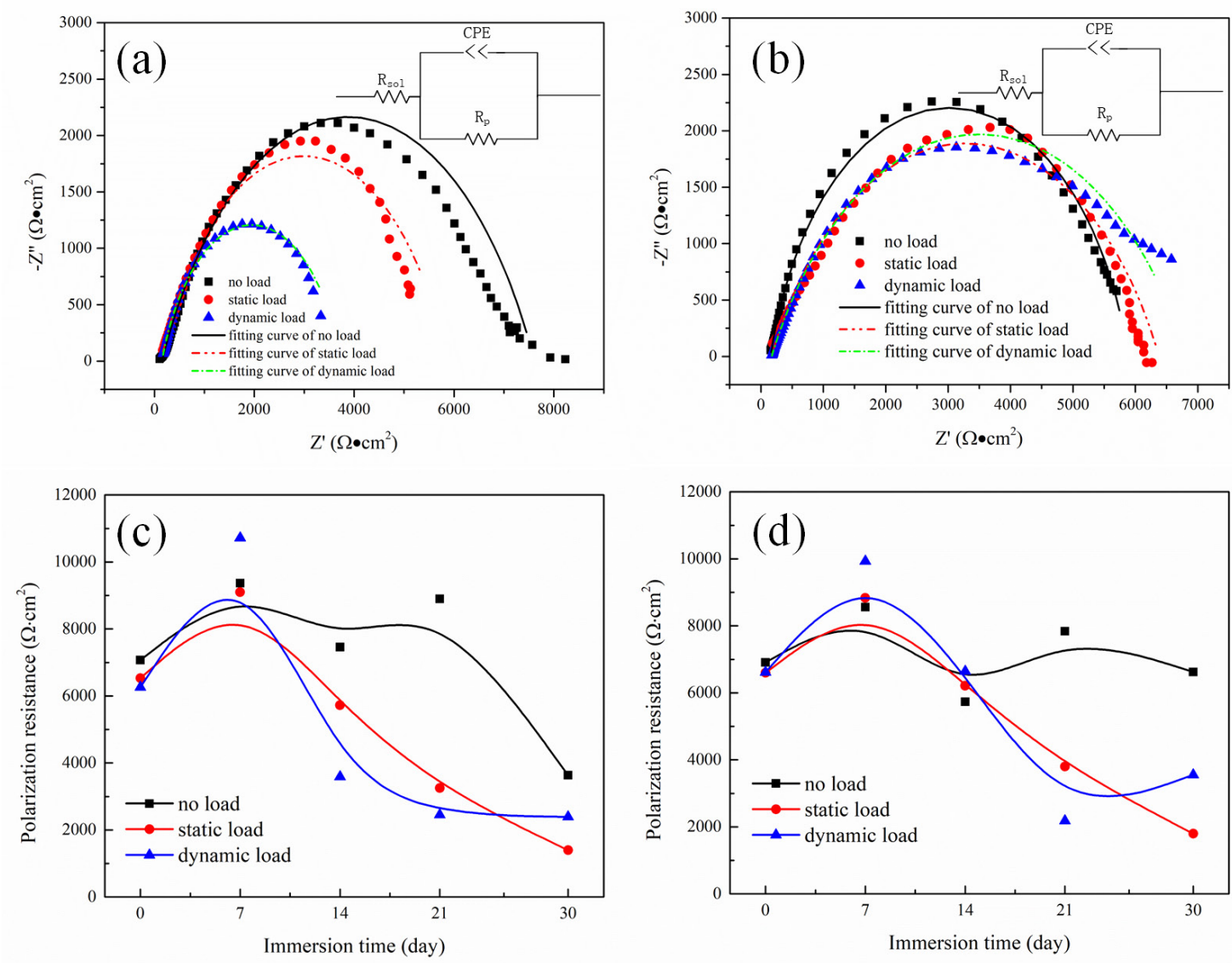

Figure 5: Electrochemical behavior of the wire inside the composite during immersion: (a) Nyquist plots and the fitting curves of the wire inside the composite at 10 vol\% after immersion for 14 days under different load modes and the right-upper image is the applied equivalent circuit model; (b) Nyquist plots and the fitting curves of the wire inside the composite at 20 vol\% after immersion for 14 days under different load modes and the right-upper image is the applied equivalent circuit model; (c) $R_{p}$ evolution of the wire inside the composite at 10 vol\% versus immersion time; (d) $\mathrm{R}_{p}$ evolution of the wire inside the composite at 20 vol\% versus immersion time. 

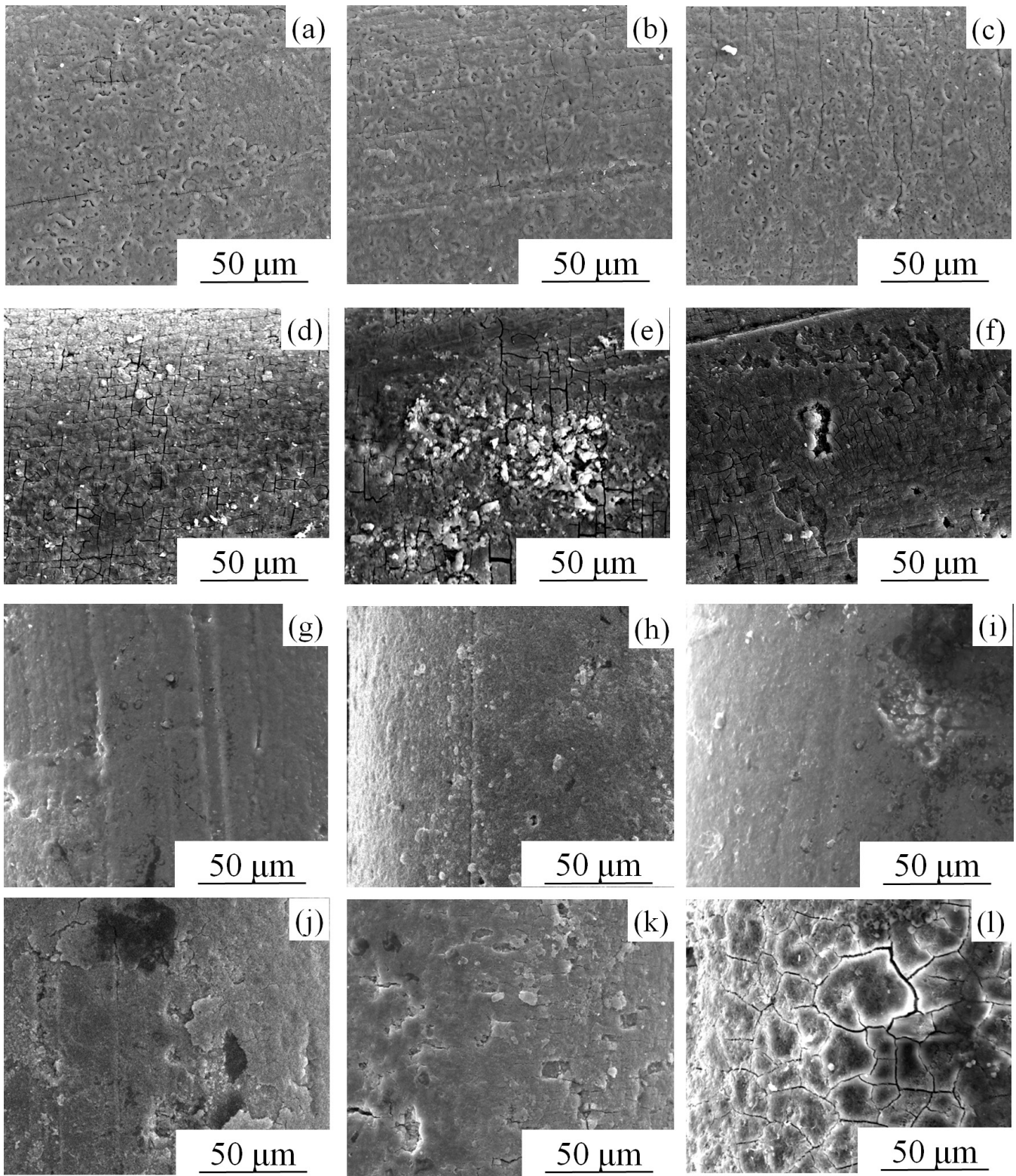

Figure 6: Surface morphologies of Mg wires in the composite: (a) at 10 vol\% under no load after 7 days immersion; (b) at 10 vol\% under static load after 7 days immersion; (c) at 10 vol\% under dynamic load after 7 days immersion; (d) at 10 vol\% under no load after 30 days immersion; (e) at 10 vol\% under static load after 30 days immersion; (f) at 10 vol\% under dynamic load after 30 days immersion; (g) at 20 vol\% under no load after 7 days immersion; (h) at 20 vol\% under static load after 7 days immersion; (i) at 20 vol\% under dynamic load after 7 days immersion; (j) at 20 vol\% under no load after 30 days immersion; (k) at 20 vol\% under static load after 30 days immersion; (l) at 20 vol\% under dynamic load after 30 days immersion.

load could promote the coating breakage. However, it seems that the coating breakage of the wire at $20 \mathrm{vol} \%$ is slighter than that at $10 \mathrm{vol} \%$, indicating a high wire content would mitigate the breakage of the coating, meeting well with the $\mathrm{R}_{p}$ values.

Figure 7(a) and 7(c) shows the defects inside the composite at $20 \mathrm{vol} \%$ under after immersion for 21 days and 30 days under no load. The largest defect volume after 21 days immersion is about $0.37 \mathrm{~m}^{3}$, while it increases to $0.41 \mathrm{~m}^{3}$ after 30 days immersion. Additionally, it could be noticed that most of the defects mainly appear along the interface between the Mg wires and the matrix, as seen in Figure 7(b) and $7(d)$, denoting the important role of the interface for the diffusion of the small molecules and the weakening of the interface as the immersion proceeds. Moreover, the largest defects seem to emerge randomly at the end side of the composite or the part near the surface. 

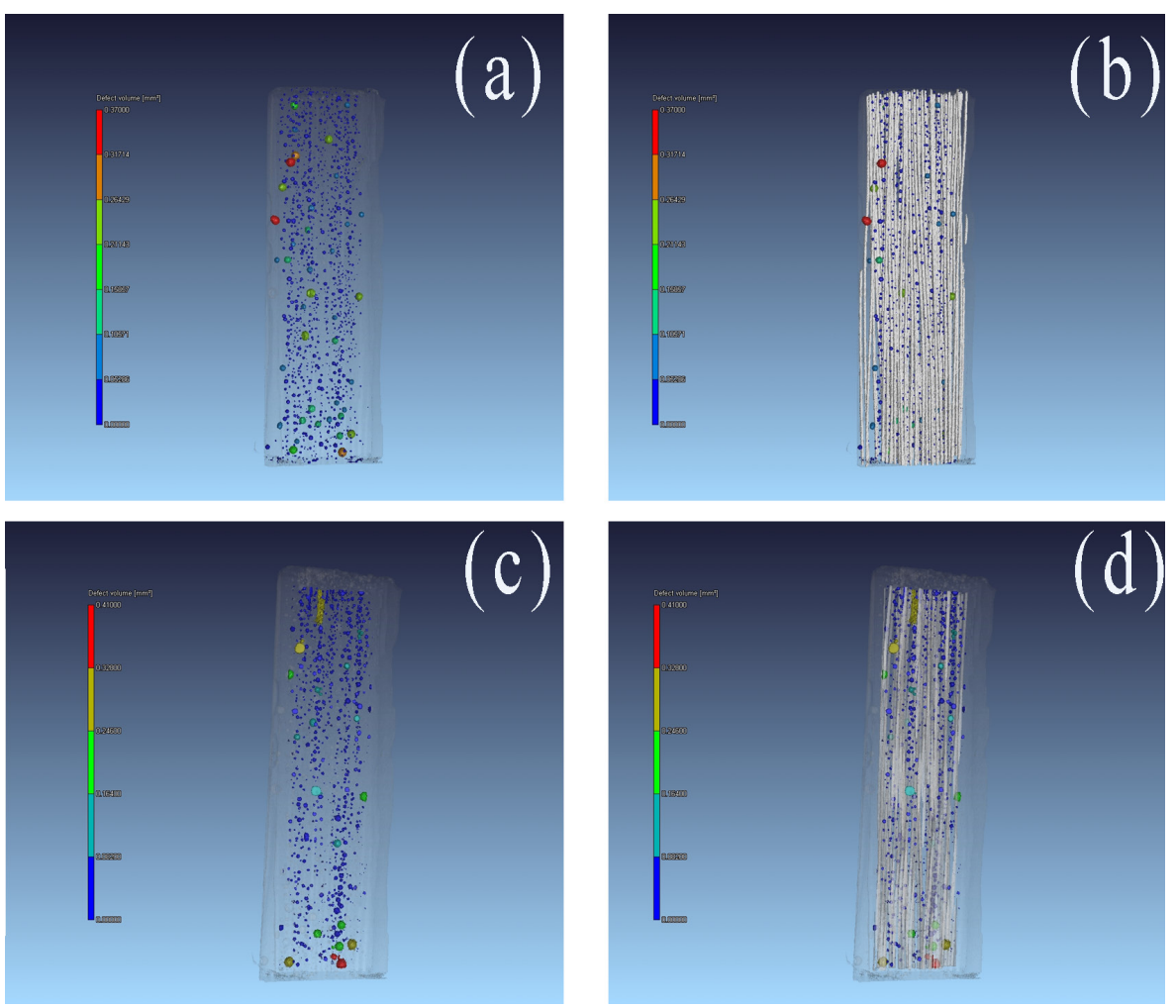

Figure 7: The distribution of the defects in the composite at 20 vol\% under no load: (a) the profile without the wires after 21 days immersion; (b) the profile including the wires after 21 days immersion; (c) the profile without the wires after 30 days immersion; (d) the profile including the wires after 30 days immersion.

\section{Discussions}

\subsection{Effect of $\mathrm{Mg}$ wire content}

It is widely accepted that the hydrolysis of PLA is strongly related to the $\mathrm{pH}$ values of the surround environment. In this work, it could be observed that the $\mathrm{pH}$ values of the solution drop significantly at a high $\mathrm{Mg}$ wire content under loading conditions during the initial immersion. This is probably attributed to the large interface area between the wires and the matrix at a high $\mathrm{Mg}$ wire content, which would be one of the main diffusion pathways for the small molecules. However, as the immersion proceeds, the $\mathrm{pH}$ values would gradually increase at a high $\mathrm{Mg}$ wire content, suggesting the degradation of $\mathrm{Mg}$ wires could mitigate the $\mathrm{pH}$ decrease originated from the degradation of PLA.

According to this study, it seems that $\mathrm{Mg}$ wires in the composite at $20 \mathrm{vol} \%$ experiences lower degradation rate than that at $10 \mathrm{vol} \%$ after 30 days immersion, which may contribute to retain the strength. The low degradation rate of the wire at a high wire content is probably attributed to the high $\mathrm{pH}$ value inside the composite. However, during the immersion, small defects preferred to appear along the interface between the wire and the matrix, which may further decrease the interface properties of the composite. This counter reaction leads to the approximate strength retention for the composite at $10 \mathrm{vol} \%$ and $20 \mathrm{vol} \%$ under no load. Additionally, it could be noticed that the largest defect preferred to appear at the peripheral outer surface rather than the two ends of the composite. This result may suggest the end sealing treatment would not be essential for the composite at a high wire content or with other composite structure [25], though this may increase the diffusion pathways of water from the two ends of the composite.

\subsection{Effect of load mode}

According to the study, external load significantly influences the degradation behaviors of the composite and its components. In this study, the specimens subjected to static and dynamic load undergo a significant reduction in $\mathrm{pH}$ values and bending strength compared to those under no load. For the PLA matrix, the lower $\mathrm{pH}$ value may indicate a higher degradation rate of the PLA matrix under external load conditions, specially under dynamic load. This is probably attributed to the decreased activation energy $[26,27]$ 
and promoted motion of chain segments induced by external load [28]. Intersetingly, the $\mathrm{R}_{p}$ of $\mathrm{Mg}$ wire in the composite firstly increases after immersion for 7 days. This is probably attributed to the formation of inter- or intramolecular crosslinks induced by the interaction between $\mathrm{Mg} 2+$ ions from $\mathrm{Mg}$ fillers and the carboxylic acid groups from the degradation of PLA matrix [29]. Under the condition of dynamic loading, this interaction would be more significant, which would further decrease the solubility of PLA matrix, leading the largest Rp after immersion for 7 days. As the immersion proceeds, $\mathrm{Mg}$ wires would degrade faster under static and dynamic load.

However, the degradation rate of $\mathrm{Mg}$ wires under dynamic load is dramatically larger than that under static load after 30 days immersion. This result is consistent with the $\mathrm{pH}$ values, which represents a larger value under dynamic load. As noted above, dynamic load could increase convective transport of degradation products, specially the acid degradation products out of the composite. Therefore, the results may indicate the $\mathrm{pH}$ value inside the composite under dynamic load would be higher than that under static load, leading to a relatively low degradation rate of $\mathrm{Mg}$ wire.

\section{Conclusions}

Degradable Mg wires /PLA composite are prepared for bone fixation implantation. A high wire content could apparently enhance the mechanical properties of the composite and mitigate the degradation of $\mathrm{Mg}$ wires in the composite. The external load is found to significantly affect the in vitro performances of the composite and its components. Dynamic load could enhance the bending strength loss of the composite and the transport of acidic degradation products out of the composite, which would further retard the degradation of the inside $\mathrm{Mg}$ alloy wire components.

Acknowledgement: This work was supported by the Natural Science Foundation of Jiangsu Province (Grant No. BK20181020), the introduction of Talent Research Fund in Nanjing Institute of Technology (Grant No.YKJ201705) and the General Medical Research Project of Jiangsu Committee of Health (Grant No. H2019022).

\section{References}

[1] G. Narayanan, V.N. Vernekar, E.L. Kuyinu, C.T. Laurencin, Poly (lactic acid)-based biomaterials for orthopaedic regenerative engineering, Adv. Drug Del. Rev. 107 (2016) 247-276.

[2] Z. Sheikh, S. Najeeb, Z. Khurshid, V. Verma, H. Rashid, M. Glogauer, Biodegradable materials for bone repair and tissue engineering applications, Materials (Basel) 8(9) (2015) 5744-5794.

[3] Y. Ramot, M. Haim-Zada, A.J. Domb, A. Nyska, Biocompatibility and safety of PLA and its copolymers, Adv. Drug Del. Rev. 107 (2016) 153-162.

[4] J. Liuyun, X. Chengdong, C. Dongliang, J. Lixin, P. xiubing, Effect of $n-H A$ with different surface-modified on the properties of $n$ HA/PLGA composite, Appl. Surf. Sci. 259(Supplement C) (2012) 72-78.

[5] J.J. Blaker, A. Bismarck, A.R. Boccaccini, A.M. Young, S.N. Nazhat, Premature degradation of poly ( $\alpha$-hydroxyesters) during thermal processing of Bioglass ${ }^{\circledR}$-containing composites, Acta Biomater. 6(3) (2010) 756-762.

[6] Y. Chen, S.H. Ye, H. Sato, Y. Zhu, V. Shanov, T. Tiasha, A. D’Amore, S. Luketich, G. Wan, R. Wagner William, Hybrid scaffolds of Mg alloy mesh reinforced polymer/extracellular matrix composite for critical-sized calvarial defect reconstruction, J. Tissue Eng. Regen. Med. 12(6) (2018) 1374-1388.

[7] S.C. Cifuentes, E. Frutos, R. Benavente, V. Lorenzo, J.L. GonzálezCarrasco, Assessment of mechanical behavior of PLA composites reinforced with $\mathrm{Mg}$ micro-particles through depth-sensing indentations analysis, J. Mech. Behav. Biomed. 65 (2017) 781-790.

[8] X. Li, W. Yu, L. Han, C. Chu, J. Bai, F. Xue, Degradation behaviors of $\mathrm{Mg}$ alloy wires/PLA composite in the consistent and staged dynamic environments, Mat Sci Eng C 103 (2019) 109765.

[9] H. Cai, J. Meng, X. Li, F. Xue, C. Chu, C. Guo, J. Bai, In vitro degradation behavior of $\mathrm{Mg}$ wire/poly(lactic acid) composite rods prepared by hot pressing and hot drawing, Acta Biomater. 98 (2019) 125-141.

[10] C. Zhao, H. Wu, J. Ni, S. Zhang, X. Zhang, Development of PLA/Mg composite for orthopedic implant: Tunable degradation and enhanced mineralization, Composites Sci. Technol 147 (2017) 8-15.

[11] C.C. Daw, K. Ramachandran, B.T. Enslow, S. Maity, B. Bursic, M.J. Novello, C.S. Rubannelsonkumar, A.H. Mashal, J. Ravichandran, T.M. Bakewell, W. Wang, K. Li, T.R. Madaris, C.E. Shannon, L. Norton, S. Kandala, J. Caplan, S. Srikantan, P.B. Stathopulos, W.B. Reeves, M. Madesh, Lactate elicits ER-Mitochondrial Mg2+ dynamics to integrate cellular metabolism, Cell 183(2) (2020) 474-489.e17.

[12] V. Piemonte, F. Gironi, Kinetics of hydrolytic degradation of PLA, J. Polym. Environ. 21(2) (2013) 313-318.

[13] T.M. Skerry, Mechanical loading and bone: What sort of exercise is beneficial to the skeleton?, Bone 20(3) (1997) 179-181.

[14] L.E. Lanyon, Using functional loading to influence bone mass and architecture: objectives, mechanisms, and relationship with estrogen of the mechanically adaptive process in bone, Bone 18(1, Supplement 1) (1996) S37-S43.

[15] A.G. Robling, F.M. Hinant, D.B. Burr, C.H. Turner, Improved bone structure and strength after long-term mechanical loading is greatest if loading is separated into short bouts, J. Bone Miner. Res 17(8) (2002) 1545-1554.

[16] J. Wolf, W.W. A., A.P.M. M., S.W. O., Comparison of cyclic loading versus constant compression in the treatment of long-bone fractures in rabbits, J. Bone Joint Surg AM 63(5) (1981) 805-810.

[17] P. Li, X. Feng, X. Jia, Y. Fan, Influences of tensile load on in vitro degradation of an electrospun poly(l-lactide-co-glycolide) scaffold, Acta Biomater. 6(8) (2010) 2991-2996. 
[18] D. Hayman, C. Bergerson, S. Miller, M. Moreno, J.E. Moore, The effect of static and dynamic loading on degradation of PLLA stent fibers, J. Biomech. Eng. 136(8) (2014) 081006.

[19] L. Choudhary, R.K. Singh Raman, Magnesium alloys as body implants: Fracture mechanism under dynamic and static loadings in a physiological environment, Acta Biomater. 8(2) (2012) 916 923.

[20] Q. Tian, J. Antonio Mendeza, L. Rivera-Castaneda, O. Mahmood, A. Showalter, E. Ang, S. Kazmi, H. Liu, Development of a novel loading device for studying magnesium degradation under compressive load for implant applications, Mater. Lett 217 (2018) 27-32.

[21] C.L. Chu, X. Han, J. Bai, F. Xue, P.K. Chu, Fabrication and degradation behavior of micro-arc oxidized biomedical magnesium alloy wires, Surf. Coat. Technol. 213 (2012) 307-312.

[22] X. Li, C.L. Chu, L. Liu, X.K. Liu, J. Bai, C. Guo, F. Xue, P.H. Lin, P.K. Chu, Biodegradable poly-lactic acid based-composite reinforced unidirectionally with high-strength magnesium alloy wires, Biomaterials 49(0) (2015) 135-144.

[23] N.T. Kirkland, N. Birbilis, Magnesium Biomaterials: Design, Testing, and Best Practice, Springer, Switzerland, 2014.

[24] X. Li, C. Qi, L. Han, C. Chu, J. Bai, C. Guo, F. Xue, B. Shen, P.K. Chu, Influence of dynamic compressive loading on the in vitro degradation behavior of pure PLA and Mg/PLA composite, Acta Biomater. 64(Supplement C) (2017) 269-278.
[25] B. Mortazavi, H. Yang, F. Mohebbi, G. Cuniberti, T. Rabczuk, Graphene or h-BN paraffin composite structures for the thermal management of Li-ion batteries: A multiscale investigation, Appl Energ 202 (2017) 323-334.

[26] D.A. Davis, A. Hamilton, J. Yang, L.D. Cremar, D. Van Gough, S.L. Potisek, M.T. Ong, P.V. Braun, T.J. Martinez, S.R. White, J.S. Moore, N.R. Sottos, Force-induced activation of covalent bonds in mechanoresponsive polymeric materials, Nature 459(7243) (2009) 68-72.

[27] M.K. Beyer, H. Clausen-Schaumann, Mechanochemistry: the mechanical activation of covalent bonds, Chem. Rev. 105(8) (2005) 2921-2948.

[28] A.Z. Kharazi, M.H. Fathi, F. Bahmani, H. Fanian, Nonmetallic textile composite bone plate with desired mechanical properties, J. Compos. Mater. 46(21) (2012) 2753-2761.

[29] H. Al-Hashim, A. Kasha, W. Abdallah, B. Sauerer, Impact of modified seawater on zeta potential and morphology of calcite and dolomite aged with stearic acid, Energ Fuel 32(2) (2018) 16441656. 